\title{
Neutral Theory: Applicability and Neutrality of Clinical Study Endpoints Where a Disease-Specific Instrument is Available
}

Ravi Jandhyala ( $\sim$ ravi@medialis.co.uk)

King's College London - Strand Campus: King's College London https://orcid.org/0000-0002-72417476

\section{Research Article}

Keywords: disease activity score, disease-specific severity, disease assessment, construct, Neutral Theory

Posted Date: March 8th, 2022

DOI: https://doi.org/10.21203/rs.3.rs-1392369/v1

License: (c) (i) This work is licensed under a Creative Commons Attribution 4.0 International License.

Read Full License 


\section{Abstract \\ Background:}

Disease scoring tools/constructs are designed to accurately measure disease status and severity but are limited by the indicators included and how they are operationalised. Neutral Theory describes the ideal construct that includes all relevant indicators - the Neutral List - and, therefore, provides complete accuracy, or Neutrality. To explore the potential of the theory, indicators from several disease-specific severity scores (DSSs) were assessed as surrogates for the Neutral List.

\section{Methods:}

Medline (PubMed) searches were undertaken for 6,804 rare diseases/conditions, listed on the Orphanet database as of 18-Jan-21, to identify those with a single, validated DSS and at least five studies assessing disease severity. The indicators included in each DSS were compared against those utilised in the respective clinical studies and the sensitivity/specificity calculated. The sum of the sensitivity/specificity represented the Neutrality score.

\section{Results:}

Ten diseases/conditions met the inclusion criteria: achalasia; Behcet's syndrome; Creutzfeldt-Jakob disease; Fournier's gangrene; Guillain-Barré syndrome; atypical hemolytic uremic syndrome; palmoplantar psoriasis; Prader-Willi syndrome; systemic lupus erythematosus; and systemic sclerosis. The total number of indicators in the DSSs ranged from 3-28 and for all diseases/conditions, additional indicators of disease severity were assessed in the clinical studies (1-36 additional). The Neutrality of the studies across all 10 diseases/conditions varied widely, with achalasia, Fournier's gangrene, palmoplantar psoriasis, systemic lupus erythematosus, and systemic sclerosis the only diseases with at least one study achieving a maximum Neutrality score of 2. None of the studies for Behcet's syndrome, Creutzfeldt-Jakob disease, atypical hemolytic uremic syndrome, and Prader-Willi syndrome achieved a Neutrality score > 1.50. Overall, the rate of false negatives increased and the rate of false positives decreased with increasing disease prevalence.

\section{Conclusions:}

Across studies of all included diseases/conditions, there was considerable variability in the accuracy or Neutrality of disease severity assessment. Neutral Theory has the potential to improve endpoint definitions and study design and its utility should be explored.

\section{Introduction}


Accurate measurement of disease status or activity is essential to assess the impact of medical interventions. Any construct for measuring disease severity, however, is vulnerable to variability in how it is operationalised by different researchers and is ultimately limited by its original conceptualisation. Whilst validation and refinement can improve the precision and accuracy of disease scores[1,2,3],variability and incomplete data capture cannot be completely eliminated. To improve reliability, the use of combined outcomes (e.g. disease scores with patient-reported outcomes [PROs])has gained traction with regulatory bodies $[4,5]$, but is more a pragmatic fix rather than a definitive solution.

A new theory recently espoused - Neutral Theory - predicates that the accuracy of a construct is a function of the relevant versus irrelevant indicators included in an observation

[6]. With regard to measuring the construct of disease severity, pivotal to the theory is the creation of a Neutral, or exhaustive, list of all relevant indicators for a particular disease phenotype. The Neutral List for any disease phenotype requires extensive research and the method of operationalisation to accomplish this has not yet been described [6]. Disease-specific indices can be considered the closest constructs currently available to achieving Neutrality and a (non-Neutral) surrogate under which to assess the accuracy of disease assessment under the conditions of Neutral Theory. A recently published study found that generichealth-related quality of life (HRQOL) tools, the SF-36 and EQ-5D, correlated poorly with disease/condition-specific tools (neither achieving sensitivity/specificity both $>50 \%$ vs 163disease/condition-specific tools) [7].This indicates thatthe adoption of Neutral Theory in the development and refinement of HRQoL tools could improve their accuracy and therebyprovidemore reliable assessments for evaluating the impact of a disease and its treatment on patient utility.

To explore thepotential of the theory further, in this study, the indicators included in disease-specific severity scores (DSSs) for a number of rare diseases were used to assess the Neutrality (accuracy) of disease assessment against endpoints from clinical studies of each disease.

\section{Methods}

\section{Rare diseases and identification of DSSs}

All 6,804 rare diseases listed on the Orphanet database [8] as of 18 January 2021 were screened for inclusion in the study. An automated search was conducted in Medline (PubMed) using the following generic search string to identify those diseases with a single, validated DSS: (rare OR uncommon OR infrequent OR orphan) AND (IIlness* OR sickness* OR infection* OR malady* OR disorder* OR condition* OR infirmity* OR abnormality*) AND (severity AND (score OR scale OR index OR activity).

Diseases/conditions were excluded if no DSS was identified or if multiple DSSs were available with no agreed gold standard to use as the Neutral list.

\section{Clinical studies evaluating disease severity}


For each of the rare diseases/conditions with a single DSS, a literature search was undertaken in Medline (PubMed), from inception to 21 January 2021, to identify studies assessing disease severity. Variations of the following search string were used within Title/Abstract: ["disease name/term" \#1" OR \#disease name/term \#2" etc] (e.g. "achalasia" OR "esophageal achalasia" OR "achalasia cardiae" OR "cardiospasm") AND ["severity"] AND ["score" OR "index" OR "instrument" OR "tool" OR "scale"] (see Additional file 1 for specific search strings). Two reviewers conducted the literature review, with the initial screening of abstracts and titles conducted using the semi-automated Rayyan tool (https://rayyan.qcri.org/) [9]. To be included in the study, at least five studies had to be identified assessing disease severity for a disease/condition.

\section{The neutrality of endpoints in clinical trials}

All indicators used to define endpoints for disease severity evaluation in each study were documented. These were then compared against the indicators included in the respective DSS identified. Indicators included in both the study and DSS were classified as overlapping, those present in only the study but not the score were classified as redundant, and those present in only the score but not the study were classified as missing. Indicators not in the study or DSS, but included as an endpoint in another study of the same disease were classified as irrelevant.

The Neutrality of the choice of indicators in a clinical study was defined in terms of sensitivity and specificity (Fig. 1 \& Table 1). Sensitivity was defined as the proportion of overlapping indicators among the total disease-specific score items $(a / a+c)$ and specificity was defined as the proportion of irrelevant indicators among the total items outside the disease-specific score items $(d / b+d)$. (The underlying assumptions of defining Neutrality are described elsewhere [6].) A Neutrality score was calculated, which was the sum of the sensitivity and specificity, with a score of 2 representing perfect Neutrality $(100 \%$ sensitivity and $100 \%$ specificity) and $>1.50$ good Neutrality. Based on the Neutrality of a choice of items (sensitivity and specificity) and the prevalence of severe disease (set at $20 \%, 50 \%$, and $80 \%$ ), the rates of false negatives and false positives were evaluated using the sample sizes as reported in the clinical studies. All analyses were performed using R 3.6.0 (R Core Team, 2021) and Microsoft Excel 365 (Microsoft).

Table 1

Choice of indicators to assess disease severity in a clinical study evaluated against those included in the respective DSS and calculation of Neutrality

\begin{tabular}{|lll|}
\hline Indicators in a clinical study & Indicators within DSS & Indicators outside DSS \\
\hline Included & Overlap $(a)$ & Redundant $(b)$ \\
\hline Excluded & Missing $(c)$ & Irrelevant $(d)$ \\
\hline Total & $(a+c)$ & $(b+d)$ \\
\hline Neutrality (accuracy) & Sensitivity: $a / a+c$ & Specificity: $d / b+d$ \\
\hline DSS: Disease-specific score & & \\
\hline
\end{tabular}




\section{Results}

\section{Included rare diseases and DSS}

A total of 24 rare diseases/conditions met the screening criteria of having a single, validated DSS: achalasia; alkaptonuria; Batten disease; Behcet's syndrome; Creutzfeldt-Jakob disease; cutaneous lupus erythematosus; dialysis-related amyloidosis; Fournier's gangrene; Guillain-Barré syndrome; atypical hemolytic uremic syndrome; Hirschsprung's disease; hyperhidrosis; familial dysautonomia; Kennedy's disease; Langerhans cell histiocytosis; palmoplantar psoriasis; Pfeiffer syndrome; Pierre Robin syndrome; Prader-Willi syndrome; Rett syndrome; Smith-Lemli-Opitz syndrome; systemic sclerosis; systemic lupus erythematosus; and systemic sclerosis.

The disease-specific searches identified 1,290 publications (Fig. 2), from which 11 of the 24 rare diseases/conditions were found to have at least five studies assessing disease severity. Hyperhidrosis was excluded, however, as the disease can be primary (idiopathic) or secondary to another condition, and there was found to be a lack of clarification on what aetiology was being assessed for severity. Thus, 10 diseases/conditions were included in the study each with a corresponding DSS, totalling 133 distinct studies: achalasia (27 studies; DSS: Eckardt Score); Behcet's syndrome (21; Krause's Behçet's disease activity assessment [KBDAA]); Creutzfeldt-Jakob disease (5; Creutzfeldt-Jakob disease neurological status scale [CJD-NS]); Fournier's gangrene (5; Fournier's Gangrene Severity Index [FGSI]); Guillain-Barré syndrome (6; Guillain-Barré rating scale [GBRS]); atypical hemolytic uremic syndrome (6; Pediatric Neurologic Assessment Score for hemolytic uremic syndrome [PNAS-HUS]); palmoplantar psoriasis (5; Palmoplantar Psoriasis Area and Severity Index [PPPASI]); Prader-Willi syndrome (8; Prader-Willi syndrome Behavioral Questionnaire [PWSBQ]); systemic lupus erythematosus (22; lupus severity index [LSI]); systemic sclerosis (28; Modified Rodnan skin score [mRSS]) (Table 2). The indicators comprising each score formed the surrogate Neutral list for the respective diseases.

\section{Table 2: Overview of included diseases and disease-specific severity scores}




\begin{tabular}{|c|c|c|}
\hline Rare disease & Clinical particulars & Disease Score \\
\hline Achalasia [[1]] & $\begin{array}{l}\text { A chronic condition of } \\
\text { the oesophagus that can } \\
\text { present with dysphagia, } \\
\text { regurgitation, chest pain } \\
\text { and malnutrition }\end{array}$ & $\begin{array}{l}\text { Eckardt Score - } 4 \text { item self-report scale measuring } \\
\text { weight loss in kilograms, chest pain, regurgitation, and } \\
\text { dysphagia. Each item is graded on a score of } 0 \text { to } 3 \text {, } \\
\text { with a maximum score of } 12 \text {. Scores } \geq 3 \text { are } \\
\text { considered suggestive of active achalasia }\end{array}$ \\
\hline $\begin{array}{l}\text { Behcet's } \\
\text { syndrome [[1]] }\end{array}$ & $\begin{array}{l}\text { A multisystem disorder, } \\
\text { the clinical expression of } \\
\text { which may be } \\
\text { dominated by } \\
\text { mucocutaneous, } \\
\text { articular, neurologic, } \\
\text { urogenital, vascular, } \\
\text { intestinal, or pulmonary } \\
\text { manifestations }\end{array}$ & $\begin{array}{l}\text { KBDAA - disease severity scored as the sum of } 1 \\
\text { point for each of the defined mild symptoms ( } 9 \text { listed), } \\
2 \text { points for each of the defined moderate symptoms } \\
\text { ( } 4 \text { listed), and } 3 \text { points for each of the defined severe } \\
\text { disease manifestations ( } 7 \text { listed) }\end{array}$ \\
\hline $\begin{array}{l}\text { Creutzfeldt- } \\
\text { Jakob disease } \\
\text { [[1]] }\end{array}$ & $\begin{array}{l}\text { The most common } \\
\text { human prion disease, } \\
\text { characterised by rapidly } \\
\text { progressive multifocal } \\
\text { neurological dysfunction, } \\
\text { myoclonic jerks, and } \\
\text { severe cognitive } \\
\text { impairment }\end{array}$ & $\begin{array}{l}\text { CJD-NS - } 26 \text { item scale each representing a } \\
\text { neurological sign. Signs rated as } 0=\text { absent (if the } \\
\text { abnormal sign was not evoked), } 1=\text { mild (if the } \\
\text { abnormal sign was mild or equivocal), and } \\
2=0 \text { obvious/severe (when the sign was severe or } \\
\text { definite). Scored as total scale score (sum of all } \\
\text { scores; maximum } 52 \text { ) and system involvement score } \\
\text { (1 point per system affected) ranging from } 0 \\
\text { (apparently healthy) to } 8 \text { (all neural systems affected) }\end{array}$ \\
\hline $\begin{array}{l}\text { Fournier's } \\
\text { gangrene [[1], } \\
\text { [1]] }\end{array}$ & $\begin{array}{l}\text { A fulminant and life- } \\
\text { threatening condition } \\
\text { characterised by } \\
\text { necrotising fasciitis of } \\
\text { perianal and } \\
\text { genitourinary regions }\end{array}$ & $\begin{array}{l}\text { FGSI - } 9 \text { parameter scale wherein the degree of } \\
\text { deviation from normal was graded from } 0 \text { to } 4 \text {. The } \\
\text { sum of the individual values represents the severity } \\
\text { index score. }\end{array}$ \\
\hline $\begin{array}{l}\text { Guillain-Barré } \\
\text { syndrome [11]] }\end{array}$ & $\begin{array}{l}\text { A syndrome } \\
\text { characterised by acute } \\
\text { rapidly progressive } \\
\text { symmetric weakness of } \\
\text { distal limbs with or } \\
\text { without sensory deficits, } \\
\text { involvement of } \\
\text { respiratory muscles, } \\
\text { cranial nerve-innervated } \\
\text { muscles, or autonomic } \\
\text { function }\end{array}$ & $\begin{array}{l}\text { GBRS - } 10 \text { item scale covering motor function, cranial } \\
\text { nerve function, and autonomic function. }\end{array}$ \\
\hline $\begin{array}{l}\text { Atypical } \\
\text { hemolytic } \\
\text { uremic } \\
\text { syndrome } \\
\text { (HUS) [11],[1] }\end{array}$ & $\begin{array}{l}\text { HUS is defined by the } \\
\text { triad of mechanical } \\
\text { hemolytic anemia, } \\
\text { thrombocytopenia and } \\
\text { renal impairment. } \\
\text { Atypical HUS (aHUS) } \\
\text { defines non-Shiga-toxin- } \\
\text { HUS }\end{array}$ & $\begin{array}{l}\text { PNAS-HUS - } 12 \text { item scale, wherein clinical variables } \\
\text { are scored from } 0 \text { (absence of the symptom) to } 3 \\
\text { (maximum symptom expression). A further score of } 1 \\
\text { for each neuro-radiological examination (MRI or CT } \\
\text { scan of the brain) and 0.5 for each } \\
\text { electroencephalogram (EEG) is added to the obtained } \\
\text { value, regardless of pathological severity finding }\end{array}$ \\
\hline Palmoplantar & A clinical subtype of & PPPASI - measures erythema, induration, and \\
\hline
\end{tabular}




\begin{tabular}{|c|c|c|}
\hline psoriasis [[1]] & $\begin{array}{l}\text { psoriasis localised on the } \\
\text { palms and soles }\end{array}$ & $\begin{array}{l}\text { desquamation on a scale of } 0-4,4 \text { being the most } \\
\text { severe }\end{array}$ \\
\hline $\begin{array}{l}\text { Prader-Willi } \\
\text { syndrome [[1]] }\end{array}$ & $\begin{array}{l}\text { A genetic multisystem } \\
\text { disorder with various } \\
\text { medical, cognitive, } \\
\text { behavioural and } \\
\text { psychiatric problems }\end{array}$ & $\begin{array}{l}\text { PWSBQ - } 37 \text { item questionnaire based on the } \\
\text { classification of the typical behavioural and emotional } \\
\text { symptoms into } 5 \text { domains. Each item is rated on a } 5- \\
\text { point scale, from } 0 \text { (not true) to } 4 \text { (extremely true). } 8 \text { of } \\
\text { the items are not included in the total score }\end{array}$ \\
\hline $\begin{array}{l}\text { Systemic } \\
\text { lupus } \\
\text { erythematosus } \\
\text { [1],[1]] }\end{array}$ & $\begin{array}{l}\text { A chronic, heterogeneous } \\
\text { autoimmune disease } \\
\text { characterised by a } \\
\text { fluctuating clinical } \\
\text { course and multiorgan } \\
\text { inflammation that can be } \\
\text { resistant to therapy and } \\
\text { often leads to end organ } \\
\text { damage }\end{array}$ & $\begin{array}{l}\text { LSI - ranges from } 0-10 \text { and is calculated using the } \\
\text { American College of Rheumatology classification } \\
\text { criteria }\end{array}$ \\
\hline $\begin{array}{l}\text { Systemic } \\
\text { sclerosis [[1], } \\
\text { [1]] }\end{array}$ & $\begin{array}{l}\text { An immune-mediated } \\
\text { rheumatic disease that is } \\
\text { characterised by fibrosis } \\
\text { of the skin and internal } \\
\text { organs and vasculopathy }\end{array}$ & mRSS - 10 item score covering 17 different areas \\
\hline
\end{tabular}

KBDAA: Krause's Behçet's disease activity assessment; CJD-NS: Creutzfeldt-Jakob disease neurological status scale; FGSI: Fournier's Gangrene Severity Index; GBRS: Guillain-Barré rating scale; mRSS: Modified Rodnan skin score; PNAS-HUS: Pediatric Neurologic Assessment Score for hemolytic uremic syndrome; PPPASI: Palmoplantar Psoriasis Area and Severity Index; PWSBQ: Prader-Willi syndrome Behavioral Questionnaire; LSI: lupus severity index

\section{The neutrality of endpoints in clinical trials}

The total number of indicators in the DSS ranged from 28 in the PWSBQ to 3 in the PPPASI (Table 3). For all 10 rare diseases/conditions, additional indicators of disease severity, not included in the DSS, were assessed in the clinical studies. This was most apparent for achalasia, systemic sclerosis and systemic lupus erythematosus, where a total of 36,28 and 24 additional indicators were assessed in the identified studies, respectively. Considerably fewer additional indicators were identified for palmoplantar psoriasis (one additional) and Creutzfeldt-Jakob disease (4 additional). 
Table 3

The number of indicators in the disease-specific severity scores and the total number of additional indicators assessed in the clinical studies for each rare disease

\begin{tabular}{|c|c|c|}
\hline Disease ( $\mathrm{N}$ studies) & Indicators in DSS* & Indicators outside DSS \\
\hline Achalasia (27) & 4 & 36 \\
\hline Behcet's syndrome (21) & 20 & 18 \\
\hline Creutzfeldt-Jakob disease (5) & $25^{\dagger}$ & 4 \\
\hline Fournier's gangrene (5) & 9 & 11 \\
\hline Guillain-Barré syndrome (6) & $11^{\ddagger}$ & 9 \\
\hline Atypical hemolytic uremic syndrome (6) & 12 & 16 \\
\hline Palmoplantar psoriasis (5) & 3 & 1 \\
\hline Prader-Willi syndrome (8) & $28^{\wedge}$ & 11 \\
\hline Systemic lupus erythematosus (22) & 24 & 24 \\
\hline Systemic sclerosis (28) & 10 & 28 \\
\hline \multicolumn{3}{|c|}{$\begin{array}{l}\text { *Eckardt Score (achalasia); Krause's Behçet's disease activity assessment (Behcet's syndrome); } \\
\text { Creutzfeldt-Jakob disease neurological status scale (Creutzfeldt-Jakob disease); Fournier's Gangrene } \\
\text { Severity Index (Fournier's gangrene); Guillain-Barré rating scale (Guillain-Barré syndrome); Pediatric } \\
\text { Neurologic Assessment Score for hemolytic uremic syndrome (atypical hemolytic uremic syndrome); } \\
\text { Palmoplantar Psoriasis Area and Severity Index (palmoplantar psoriasis); Prader-Willi syndrome } \\
\text { Behavioral Questionnaire (Prader-Willi syndrome); lupus severity index (systemic lupus } \\
\text { erythematosus; Modified Rodnan skin score (systemic sclerosis). }{ }^{\dagger} \text { Two items - hyporeflexia and } \\
\text { areflexia - were merged in line with some versions of the score. }{ }^{\ddagger} \text { This includes abnormal sweating, } \\
\text { which was removed from the final published score but included here as part of the Neutral List. ^Two } \\
\text { items - Small hands (<25th percentile) and/or feet (< } 10 \text { th percentile) for height age - were merged } \\
\text { in line with some versions of the score. }\end{array}$} \\
\hline
\end{tabular}

The Neutrality of the studies across all 10 diseases/conditions varied widely, with achalasia (Neutrality: 0.86-2.00; sensitivity: 0-100\%; specificity: $86-100 \%)$, Fournier's gangrene $(0.45-2.00 ; 0-100 \%$; specificity: $45-100 \%)$, palmoplantar psoriasis $(0.00-2.00 ; 0-100 \% ; 0-100 \%)$, systemic lupus erythematosus (0.83-2.00; 4-100\%; 79-100\%), and systemic sclerosis $(0.82-2.00 ; 0-100 \% ; 82-100 \%)$ the only diseases with at least one study achieving a maximum Neutrality score of 2 (Table 4). For these five diseases/conditions, the proportion of studies achieving a Neutrality score of $>1.50$ was $80 \%(4 / 8)$ for palmoplantar psoriasis, $66.7 \%$ (18/27) for achalasia, $59.1 \%(13 / 22)$ for systemic lupus erythematosus, $42.9 \%$ (12/28) for systemic sclerosis, and 40.0\% (2/5) for Fournier's gangrene (Additional file 2). For the remaining diseases/conditions, one of the studies $(1 / 6 ; 16.7 \%)$ for Guillain-Barré syndrome achieved a Neutrality score of $>1.50$, whilst none of the studies for Behcet's syndrome (0/21), CreutzfeldtJakob disease (0/5), atypical hemolytic uremic syndrome (0/6), and Prader-Willi syndrome (0/8) met this threshold. 
Page 9/17 


\section{Disease

(sensitivity, specificity)

\section{Achalasia}

Most Neutral study $\quad(4,0,0,36)$

$2.00(1.00,1.00)$

Least Neutral

study

$(0,5,4,31)$

$0.86(0.00,0.86)$

\section{Behcet's disease}

Most Neutral study $\quad(2,0,18,18)$

$1.10(0.10,1.00)$

Least Neutral

$(0,7,20,11)$

$0.61(0.00,0.61)$

study

\section{Creutzfeldt-Jakob disease}

$\begin{array}{lll}\text { Most Neutral study } & (3,1,22,3) & 0.87(0.12,0.75) \\ \begin{array}{l}\text { Least Neutral } \\ \text { study }\end{array} & (0,1,25,3) & 0.75(0.00,0.75)\end{array}$

\section{Fournier's gangrene}

Most Neutral study

$(9,0,0,11)$

$2.00(1.00,1.00)$

Least Neutral

$(0,6,9,5)$

$0.45(0.00,0.45)$

study

\section{Guillain-Barré syndrome}

Most Neutral study $\quad(10,1,1,8)$

$1.80(0.91,0.89)$

Least Neutral study

$(0,6,11,3)$

$0.33(0.00,0.33)$

Atypical hemolytic uremic syndrome

Most Neutral study $\quad(1,6,11,10)$

$0.71(0.08,0.62)$

Least Neutral study

$(0,9,12,7)$

$0.44(0.00,0.44)$

\section{Palmoplantar psoriasis}

Most Neutral study $\quad(3,0,0,1)$

Least Neutral $\quad(0,1,3,0)$

$2.00(1.00,1.00)$

study

\section{Prader-Willi syndrome}

Most Neutral study $\quad(3,1,25,10)$

$1.02(0.11,0.91)$

Least Neutral

$(1,6,27,5)$

$0.49(0.04,0.45)$ 


\section{Systemic lupus erythematosus}
Most Neutral study
$(24,0,0,24)$
$2.00(1.00,1.00)$
Least Neutral
$(1,5,23,19)$
$0.83(0.04,0.79)$
study

\section{Systemic sclerosis}

Most Neutral study

$(10,0,0,28)$

$2.00(1.00,1.00)$

Least Neutral

$(0,5,10,23)$

$0.82(0.00,0.82)$

study

*Neutrality score calculated as the sum of the sensitivity and specificity

Few overlapping indicators and a high number of missing indicators in the study design were reflected as high rates of false positives and negatives (Fig. 3). Conversely, a low level of missing indicators reflected a low rate of false negatives, while few redundant indicators reflected a low false-positive rate (see most Neutral design for achalasia). Overall, the rate of false negatives increased and the rate of false positives decreased with increasing disease-severity prevalence.

\section{Discussion}

Neutral Theory describes a conceptual framework for measuring the accuracy of any construct against its true value, made using a Neutral List of indicators [6]. This has been applied in the context of clinical studies assessing HRQoL, where concerning differences between disease-specific and generic instruments' findings were described [7]. Efficacy is another clinically relevant endpoint and is the subject in the current study of a similar application of Neutral Theory. This time electing to apply the indicators identified in a DSS as a surrogate for the Neutral List against which Neutrality of endpoints can be modelled and predictions of the risk of misclassification of the final result can be made. Importantly, Neutrality is driven equally by sensitivity and specificity, with $100 \%$ for both indicating perfect accuracy (or Neutrality).

Ten rare diseases/conditions were reviewed and for all, the investigators selecting endpoints for measurement had elected to assess indicators included in the respective DSS and vice versa (studies informing the development of the DSS). Additional indicators outside those included in the DSS were measured for all diseases, most notably for achalasia (36 additional), systemic sclerosis (28) and systemic lupus erythematosus (24). The variability of included indicators across studies within the same disease/condition was reflected in considerable rates of false positives and false negatives (Fig. 2). Misclassification appeared to favour higher false-positive than false-negative rates, driven by the absence of overlap between the indicators in the clinical study and the corresponding DSS for the disease of interest. The high rate of false positives also reflects that these were all rare diseases/conditions, where the rate of false positives decreased with increasing prevalence of severe disease (while false-negative 
rates increased). A high false-positive rate is concerning in that such studies may be insensitive to changes in disease state either due to progression or intervention. Overall, both false positives and negatives are equally damaging for the clinical study and should be highlighted for consideration in study design.

Neutrality was achieved on occasion (5/10 diseases/conditions had a least one Neutral study), demonstrating that inclusion of a DSS in a clinical study should not be considered beyond reach. Development and utilisation of a 'Neutral' DSS in each study would enable more consistent efficacy evaluation and avoid the inter-study variation in accuracy of endpoints, as reported for the diseases/conditions assessed herein. Consideration should also be given for the inclusion of more speculative or 'redundant' constructs alongside the DSS, to enable direct comparison, as was the case when comparing generic and disease-specific HRQoL tools [7]. This can provide useful information on the possible refinement of the DSS.

The main limitation of this study was that observations herein remained in the context of the DSS being recognised as being itself non-neutral and an available surrogate for the Neutral list of the disease. The Neutrality of the DSS itself remains an important unknown. Further insights may be provided by the evaluation of diseases/conditions with more than one available and recognised DSS, both having evolved over time (disease knowledge and assessment criteria), which were excluded from the present study. Here, the influence of time on Neutrality measurements can be assessed as a function of the increase in knowledge of the relevant indicators in successive DSSs. This is a focus of ongoing research.

\section{Conclusions}

An accurate measurement of disease severity is essential for evaluating the efficacy of interventions. This study has shown that there is considerable variability in the accuracy or Neutrality of disease severity assessment within multiple rare diseases and conditions. Findings appeared consistent across all rare diseases/conditions with a DSS identified. Neutral Theory provides a conceptual framework from which to develop $100 \%$ relevant and accurate endpoints and its adoption should be considered in clinical study design.

\section{Abbreviations}

CJD-NS: Creutzfeldt-Jakob disease neurological status scale.

DSS: disease-specific severity score

FGSI: Fournier's Gangrene Severity Index.

GBRS: Guillain-Barré rating scale.

HRQoL: health-related quality of life. 
KBDAA: Krause's Behçet's disease activity assessment.

mRSS: Modified Rodnan skin score.

PNAS-HUS: Pediatric Neurologic Assessment Score for hemolytic uremic syndrome.

PPPASI: Palmoplantar Psoriasis Area and Severity Index.

PROs: patient-reported outcomes.

PWSBQ: Prader-Willi syndrome Behavioral Questionnaire; LSI: lupus severity index.

\section{Declarations}

\section{Ethics approval and consent to participate}

Not applicable

\section{Conflict of interests}

The author declares that he has no competing interests.

\section{Funding}

No funding was received for this work.

\section{Author contributions}

RJ led and came up with the concept of the study and authored and approved the manuscript.

\section{Acknowledgements}

Mohammed Kabiri, Sandra SamukthaHarikumar, and Haitam Khtiar (all Medalis) provided support for the literature searches and evidence review, sourcing the tools, and data extraction. Solomon Christopher (Medialis) conducted all the statistical analyses.

\section{References}

1. Lin TY, Ou CH, Tzai TS, et al. Validation and simplification of Fournier's gangrene severity index. Int J Urol. 2014;21(7):696-701.

2. Lewis JD, Chuai S, Nessel L, et al. Use of the Non-invasive Components of the Mayo Score to Assess Clinical Response in Ulcerative Colitis. Inflamm Bowel Dis. 2008;14(12):1660-6.

3. Taft TH, Carlson DA, TriggsJ, et al. Evaluating the reliability and construct validity of the Eckardt symptom score as a measure of achalasia severity. NeurogastroenterolMotil. 2018;30(6):e13287. 
4. U.S. Department of Health and Human Services. Food and Drug Administration. Center for Drug Evaluation and Research (CDER). Ulcerative Colitis: Clinical Trial Endpoints Guidance for Industry. Draft Guidance. August 2016. Available at: https://www.fda.gov/regulatory-information/search-fdaguidance-documents/ulcerative-colitis-clinical-trial-endpoints-guidance-industry [Accessed December 2020].

5. European Medicines Agency. Appendix 2 to the guideline on the evaluation of anticancer medicinal products in man. The use of patient-reported outcome (PRO) measures in oncology studies. Available at: https://www.ema.europa.eu/en/documents/other/appendix-2-guideline-evaluationanticancer-medicinal-products-man_en.pdf [Accessed December 2020].

6. Neutral theory: a conceptual framework for construct measurement in clinical research. https://doi.org/10.13140/RG.2.2.33212.16008. (Pre-print)

7. Jandhyala R. Neutral theory: applicability and neutrality of using generic health-related quality of life tools in diseases or conditions where specific tools are available. BMC Med Res Methodol. 2021. Apr 26;21(1):86. doi: 10.1186/s12874-021-01279-w.

8. Orphanet. Disease list. Available at: https://www.orpha.net/consor/cgibin/Disease_Search_List.php?Ing=EN. [Accessed January 2021].

9. Ouzzani M, Hammady H, Fedorowicz Z, et al. Rayyan-a web and mobile app for systematic reviews. Syst Rev. 2016;5(1):210.

\section{Figures}




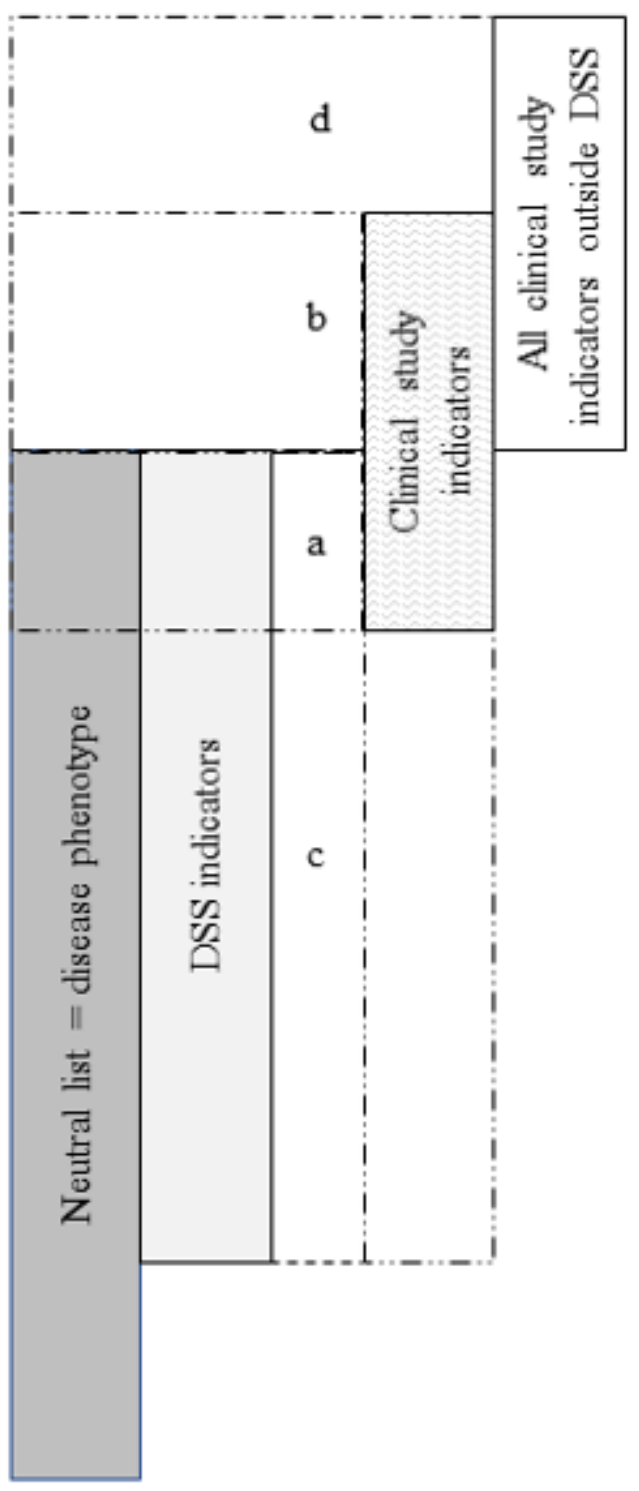

Figure 1

Orientation of the Neutral list of indicators for the disease, Disease severity score (DSS) indicators and clinical study indicators 

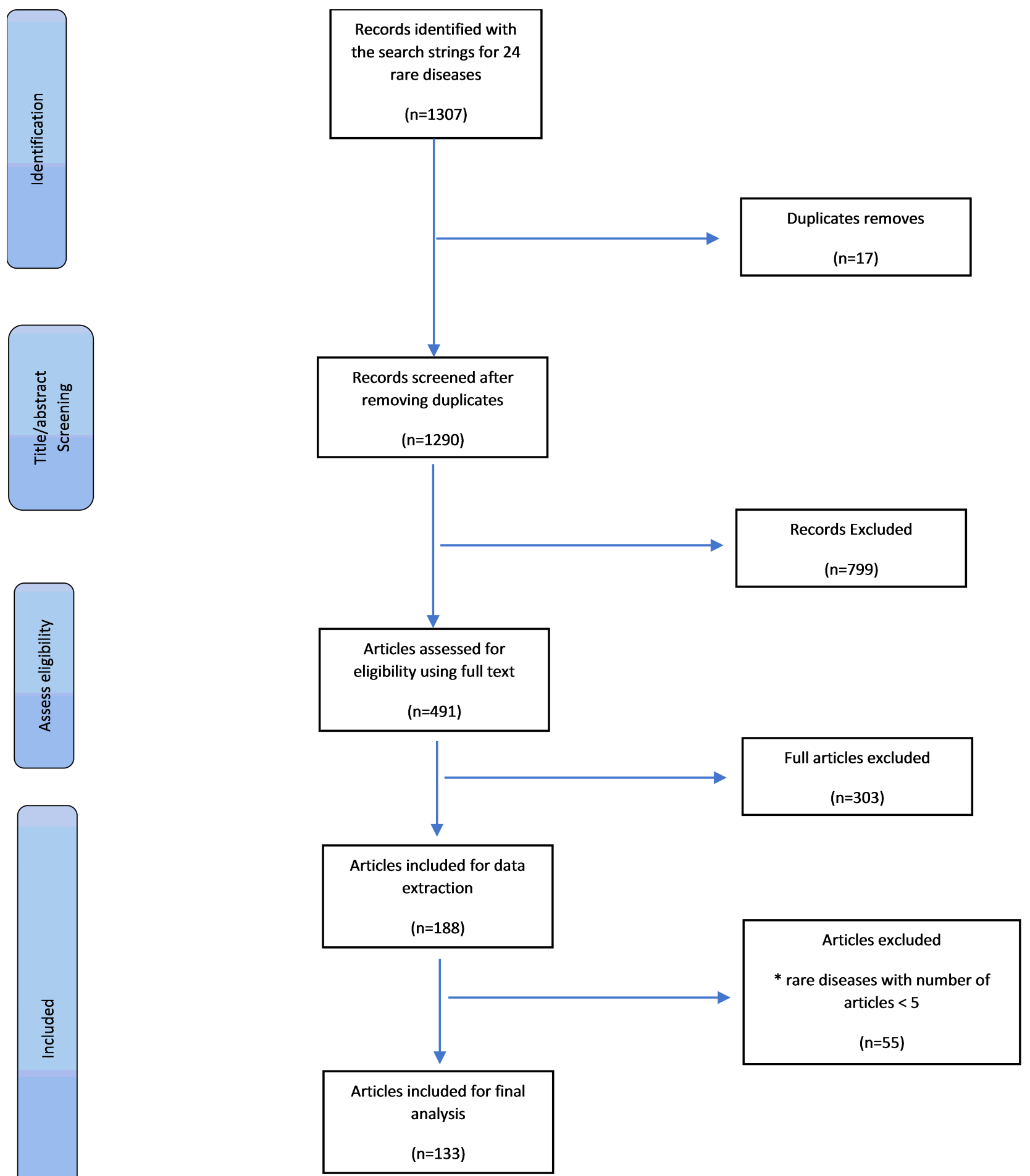

Figure 2

Overview of identification and selection of clinical studies of rare diseases

Figure 3 
Rates of false negatives and false positives at $20 \%, 50 \%$ and $80 \%$ prevalence of severe disease for the most and least Neutral studies for each disease 